\title{
A História da Ciência como estratégia metodológica no ensino aprendizagem de Física
}

The History of Science as a methodological strategy in teaching Physical Learning

\author{
J.G.S.L. Junior ${ }^{1 *}$; N.N. Soares ${ }^{2}$; L.M. Gomes ${ }^{1}$; F.C.L. Ferreira ${ }^{1}$ \\ ${ }^{1}$ Faculdade de Física/Instituto de Ciências Exatas/Programa Nacional de Mestrado Profisional em Ensino de Física, \\ Universidade Federal do Sul e Sudeste do Pará, 68507-590, Marabá-Pará, Brasil
}

${ }^{2}$ Faculdade de Matemática/Instituto de Ciências Exatas, Universidade Federal do Sul e Sudeste do Pará, CEP 68507. 590, Marabá - Pará, Brasil

*gidauto@unifesspa.edu.br

(Recebido em 19 de dezembro de 2016; aceito em 05 de janeiro de 2017)

\begin{abstract}
A inserção da História da Ciência como estratégia metodológica na educação, principalmente no ensino aprendizagem de Física, vem sendo discutida nas últimas décadas por inúmeros pesquisadores. Embora, alguns acreditem que sua utilização possa apresentar certas limitações, há aqueles que defendem sua importância no ensino. Assim, considerando o âmbito das pesquisas sobre as potencialidades do uso da História da Ciência no ensino, torna-se relevante pesquisar sobre as contribuições de algumas Teorias de Aprendizagem nesse aspecto, uma vez que, talvez por desconhecimento ou por omissão, professores apresentam concepções sobre a natureza da ciência, e de princípios Físicos elementares de forma equivocada, distorcida, reforçada por mitos científicos abordados através de uma pseudo-história, comprometendo de forma efetiva o ensino. Nesse artigo alguns livros didáticos da Rede Pública de ensino foram analisados, ressalta-se que embora alguns desses livros apresentem os aspectos históricos e filosóficos de maneira adequada, a grande maioria apresenta elementos da Pseudo-história. Nesse aspecto, este artigo visa contribuir como uma fonte de suporte a prática docente quando da inserção de elementos históricos através das aulas, auxiliados por um instrumento didático indispensável ao aprendizado, o livro.
\end{abstract}

Palavras-chave: História da Ciência, Naturezada da Ciência, Ensino de Física, Teorias de Ensino, Pseudo-história

The insertion of the History of Science as a methodological strategy in education, especially in the teaching of Physics, has been discussed in the last decades by many researchers. Although some believe that its use may present certain limitations, there are those who argue its importance in teaching. Considering the scope of research on the potential of the use of the History of Science in teaching, it is relevant to research on the contributions of some Learning Theories in this aspect, since, perhaps due to lack of knowledge or omission, teachers present conceptions about the nature of science, and elementary physical principles in a misleading, distorted way, reinforced by scientific myths addressed through a pseudo-history, effectively compromising teaching. In this article some textbooks of the Public School Network were be analyzed, it is emphasized that although some of these books present the historical and philosophical aspects properly, the great majority presents elements of pseudo-history. In this aspect, this article aims to contribute as a source of support to the teaching practice when the insertion of historical elements through the classes, aided by a didactic instrument indispensable to the learning, the book.

Keywords: History of Science, Nature of Science, Physics Teaching, Teaching Theories, Pseudo-history

\section{INTRODUÇÃO}

Ao longo dos tempos, verifica-se que o conhecimento humano é condicionado por fatores histórico-sociais que interferem intrinsicamente em seu convívio na sociedade. Da mesma forma, as fundamentações teórico-científicas não nascem em detrimento de um vazio histórico-social, entretanto, torna-se indispensável incluir como pressuposto no ensino aprendizagem de Física a discussão acerca da importância do ensino da História da Ciência, bem como apresentar suas contribuições significativas, contrapontos e tendências para o desenvolvimento da ciência de um modo geral. 
Nessa perspectiva, a História da Ciência desempenha um papel estrutural na organização do conhecimento no ensino de Física, coadunando-se não como uma simples metodologia ou mais um elemento didático-pedagógico, porém, como uma ferramenta eficaz dotada de subsídios constitutivos e necessários quanto ao processo de ensino-aprendizagem de Física.

Notadamente, verifica-se que a História da Ciência aparece como um importante aliado ao ensino de Física em que permite delinear de forma clara à dinâmica do entendimento do contexto científico da disciplina antecipando entraves à aprendizagem, tornando as aulas mais motivadoras, mostrando a Física como construção humana e não apenas como uma disciplina complexa, repleta de abstrações e com alto grau de precisão lógica, principalmente exigidos na resolução de problemas.

Desta forma, para NEVES (1992) [1], a Física, quando desprovida de sua historicidade, transforma-se em uma ciência caduca, ou seja, sem nenhum aporte histórico que fundamente seus princípios e argumentos científicos, ainda para Neves, a Física precisa das descobertas e das fontes originais do conhecimento para tal.

Nos dias atuais, o desenvolvimento no conhecimento científico-tecnológico, suas aplicações e utilidades na vida do homem são de grande importância, e a ciência tem um papel fundamental nessa questão, entretanto, um seleto grupo de indivíduos a compreende e cada vez mais se tem a dificuldade a uma linguagem e metodologia que sejam acessíveis ao ensino em todos os níveis, desde as séries iniciais até o ensino superior. Quais então seriam as possibilidades de fazer com que realmente compreendam o significado, a importância e o contexto da História da Ciência durante seu desenvolvimento e não restringi-la a nomes apenas, definições, fórmulas e exercícios matemáticos complexos a serem desenvolvidos? Nesse sentido, BASSALO (1992) [2], afirma que de certa forma uma das principais finalidades do estudo da História da Ciência é, então conhecer o passado, para entender o presente e planejar o futuro, e mais, para o autor torna-se imprescindível ao cientista manter a percepção de um ser humano, que tem qualidades, defeitos e sentimentos nessa análise.

Portanto, este artigo apresenta relevantes contribuições ao uso adequado da História da Ciência para a prática da Educação em Ciências, especificamente para o ensino aprendizagem em Física, ressaltando o seu caráter integrador no processo de construção humana e com o uso coerente de teorias de ensino que reforcem esse processo de construção. Não se trata em hipótese alguma em trocar a Física pela História, e sim, apresentar um recurso metodológico que poderá tornar o ensino de Física atrativo, fundamentado em teorias de Ensino eficazes e que fortalecem o processo, bem como, despertar o interesse pelo conhecimento científico, preenchendo as lacunas quanto ao ensino de Ciências, notadamente evidenciado pelas discussões que giram em torno da disciplina.

\section{FUNDAMENTAÇÃO TÉORICA}

\subsection{Breve histórico sobre a História da Ciência}

Não é de hoje que a inserção da História da Ciência no ensino de Ciências tem sido alvo de discussões e de pesquisas. Nos finais do século XIX alguns professores ingleses já incluíam alguns temas sobre História da Ciência nas aulas de ciências. A atitude desses professores posteriormente viria ser apoiada e reforçada pela British Association for the Advancement of Science (BAAS) quando, em 1917, em relatório defendeu a necessidade e a possibilidade de demonstrar, através da História da Ciência, que a ciência é uma atividade humana e que pode contribuir para o bem estar do indivíduo contrapondo-se aos ataques que os humanistas faziam na época a ciência. De acordo com este mesmo relatório acreditava-se ainda em certo paralelismo entre o desenvolvimento intelectual do indivíduo e o desenvolvimento histórico da ciência, baseado na existência de três fases consecutivas de desenvolvimento histórico da ciência: a fase do maravilhoso, a fase da utilidade e a fase da sistematização.

Apesar dos esforços empregados durante o século XX, houve um desenvolvimento relativamente dissociado entre a História da Ciência e o ensino de Ciências, porém, ao final do século, uma reaproximação histórica entre a História da Ciência e o ensino de Ciências passou a 
ser buscada com maior ênfase por educadores e pesquisadores. Havia relatos de como o ensino de Ciências desenvolveu-se completamente dissociado da História da Ciência de conforme MATHEWS (1995) [3].

Assim, é coerente conceber a ideia que se necessita, cada vez mais de um ensino não somente de ciências, porém também sobre ciências em que se possa discutir de fato sobre ciências.

Nesse processo de reaproximação deve se considerar também elementos importantes que, aliados a alguns "produtos finais" da ciência, tais como leis e teorias, existem os processos pelos quais o conhecimento científico é desenvolvido, sendo este, o ponto onde a História da Ciência contribui efetivamente para o ensino de Ciências especificamente ao ensino de Física.

Obviamente, há muitos outros elementos envolvidos nessa reaproximação, entretanto, uma reaproximação externa nesse sentido destacou-se: a realização da conferência First International Conference on History and Philosophy of Science, realizada na Universidade da Flórida em novembro de 1989, cujo impulso foi considerável para o estabelecimento do campo de pesquisa em História da Ciência integrando profissionais e pesquisadores de diversas áreas do conhecimento preocupados com o ensino de Ciências mais contextualizado, essa conferência veio mediar um diálogo entre essas áreas propiciando o surgimento de um periódico dedicado às abordagens históricas, filosóficas e sociólogas no ensino aprendizagem de ciências e matemática; além é claro, de uma série de conferências patrocinadas pela Sociedade Europeia de Física sobre "A História da Física e o seu ensino" realizada em Milão em 1983; mais a conferência sobre a "História da Ciência e o ensino de Ciências", realizada na Universidade de Oxford em 1987 com o apoio da Sociedade Britânica de História da Ciência e por fim o mais importante desses elementos de reaproximação: a inclusão de componentes de história em vários currículos nacionais através de uma reestruturação curricular.

Dentre as importantes reformas curriculares, nas quais a História da Ciência se insere, destacam-se a proposta brasileira representada pelos Parâmetros Curriculares Nacionais (PCN) duas propostas curriculares internacionais de maior impacto: o Currículo Nacional Britânico de Ciências e o Projeto 2061 da Associação Americana para o Progresso da Ciência (AAAS), ambas mostram as consequências da reaproximação tanto nos programas do currículo, quanto nas salas de aula.

\subsection{História da Ciência e a Reestruturação Curricular}

Atualmente, no cenário nacional, é tema recorrente nas rodas de conversa discussões a Base Nacional Curricular Comum, aliás, uma iniciativa do Ministério da Educação quanto a implementação de uma base comum no âmbito nacional com a participação de toda a sociedade, ou seja, um currículo nacional democrático e participativo. Além da base curricular, constarão nessas discussões: as formações docentes e a incorporação de elementos audiovisuais nos materiais didáticos, este último, dotado de mitos e elementos pseudo-históricos em sua maioria.

No Brasil, em conformidade com as tendências, mudanças e inovações curriculares internacionais, que sugere diretrizes aos conteúdos e potencialidades da História da Ciência no ensino de Ciências, os Parâmetros Curriculares Nacionais PCN (2000) [4], caracterizam de forma sucinta alguns objetivos a serem alcançados no que diz respeito ao ensino de Física em que a física deve vir a ser reconhecida como um processo cuja construção ocorreu ao longo da história da humanidade, impregnada de contribuições culturais, econômicas e sociais que vem resultando no desenvolvimento de diferentes tecnologias e, por sua vez, por elas sendo impulsionado.

Tratando-se de experiências internacionais destacam-se nesse sentido, o Currículo Nacional Britânico de Ciências que atende as normas e as resoluções do Conselho Britânico de Ciências (NCC), o qual reserva parte do currículo (cerca de 5\% do total) para a História da Ciência, em que os estudantes devem desenvolver seu conhecimento e entendimento sobre como pensamento científico mudou através do tempo e como a natureza desse pensamento e sua utilização são afetados pelos contextos sociais, morais, espirituais e culturais em cujo seio se desenvolve e nos Estados Unidos da América, a Associação Americana para o Progresso da Ciência (AAAS) lançou em 1985, um amplo estudo a fim de revisar o ensino de Ciências nas escolas americanas, denominado de Projeto 2061 em alusão ao período de alcance das metas estabelecidas pelo 
programa. Após quatro debates e considerações, suas recomendações foram publicadas num relatório de 12 capítulos para todos os americanos.

Para MATTHEWS (1995) [3], o Projeto 2061 demonstra convergência de ideias com a relação à necessidade de que os cursos de ciências sejam mais contextualizados, mais históricos e reflexivos, ainda acrescenta que a ênfase desse projeto consiste nas discussões acerca da objetividade e mutabilidade da ciência bem como as distinções entre a pseudociência e ciência, sem esquecer-se de discutir as provas científicas com a justificativa da teoria, o "método científico", explicação e predição, ética e organização social da ciência.

Embora não exista evidência conclusiva, a utilização da História da Ciência no ensino de Ciências parece ser potencialmente vantajosa por dois motivos: o primeiro destes motivos tem a ver com a compreensão dos conceitos, princípios, leis e teorias aceitos pela comunidade científica, podendo para isso contribuir, de modo muito particular, a História da Ciência em uma abordagem internalista. A respeito, PEDUZZI (2012) [5], esclarece que a ênfase é o desenvolvimento epistemológico da ciência, favorecendo a compreensão e o domínio sobre as teorias aceitas atualmente.

\subsection{História da Ciência e a relação com as Teorias de Ensino}

Há um consenso significativo disponível na literatura sobre a História da Ciência e as teorias ensino no que se refere à preocupação com a conjunção entre ambas, mais especificamente relacionada com desenvolvimento cognitivo e ao processo de desenvolvimento conceitual histórico. Embora não seja uma preocupação recente, inúmeras teorias de ensino surgiram a fim de abordar os conceitos e os métodos da ciência cognitiva utilizadas no estudo dos processos e da História da Ciência.

Anteriormente, estas questões preocupantes foram exploradas por Hegel em 1806, em que se evidenciava logo nas primeiras páginas de sua obra a ideia de uma dialética das teorias do conhecimento vinculada à dialética das formas históricas da consciência. Enquanto a epistemologia se desenvolve, a experiência sobre o qual o conhecimento está baseado muda vertiginosamente.

Recentemente, o tratamento mais respeitado dado a este assunto encontra-se nos escritos de Jean Piaget, Vygotsky e David Ausubel, ou seja, abordam respectivamente sobre o desenvolvimento cognitivo do indivíduo, das formas de mediação do ensino aprendizado e da aprendizagem significativa. Embora, salvo as devidas diferenças, essas teorias de ensino no campo da epistemologia genética convergem para uma hipótese plausível de que existe um paralelismo entre o progresso alcançado na organização lógica e racional do conhecimento, neste caso, a História da Ciência e os processos psicológicos formativos como, por exemplo, as concepções prévias sobre a natureza da Ciência e dos conceitos físicos elementares correspondentes.

$\mathrm{Na}$ mesma perspectiva, os elementos de mediação propostos por Vygotsky se encaixam perfeitamente a esse campo da epistemologia genética através das funções psicológicas desenvolvidas pelo indivíduo tanto superiores, quanto inferiores e assumem um papel importante no processo do seu desenvolvimento quando este adentra na linha tênue entre as zonas de desenvolvimento proximais, embora outros fatores externos contribuam para o seu desenvolvimento, a exemplo, a inter-relação entre os instrumentos e signos que o indivíduo dispõe. Ainda, existem relações dinâmicas altamente complexas entre os processos de desenvolvimento e de aprendizado, as quais não podem ser englobadas por uma formulação hipotética.

Claramente, observa-se que esse tipo de ensino através de formulações hipotéticas não funciona devido ao fato que nada proposto dessa maneira terá significado algum para o aluno, evidentemente, a aprendizagem significativa envolve a aquisição de novos significados como a própria palavra "significativa" sugere e os novos significados, por sua vez, são produtos da aprendizagem de fato significativa. Para AUSUBEL (1980) [6], estes novos significados ocorrem a medida que determinadas ideias, ao serem aprendidas, relacionam-se de forma não-arbitrária e não-literal a alguns conhecimentos relevantes existentes na estrutura cognitiva do aprendiz. 
Dessa forma, a teoria de Ausubel propõe uma estratégia para facilitar a aprendizagem, manipulando a estrutura cognitiva do aprendiz.

A estratégia envolve o uso de materiais introdutórios adequados, claros e estáveis, os quais são denominados de organizadores prévios. Estes funcionam como pontes cognitivas cuja atribuição é contribuir para que o estudante possa superar o limite entre o conhecimento prévio existente e o conhecimento a ser aprendido.

A teoria da Aprendizagem Significativa e o conceito de organizadores prévios propostos por Ausubel, incorporados a História da Ciência, especificamente ao ensino de Física, tornam-se uma ferramenta metodológica interessante ao ensino, além disso, essa ferramenta fornece parâmetros que reforçam a aquisição do conhecimento significativo e se justifica pelas mesmas razões as quais os organizadores prévios se justificam.

Por fim, entende-se que a História da Ciência e a Aprendizagem Significativa proposta por Ausubel, quando aliadas, podem contribuir para melhorar a compreensão sobre um determinado conteúdo. Desta forma, a aquisição mecânica de fórmulas, equações e expressões físicas que, muitas vezes, os alunos decoram e utilizando sem compreender o seu significado real e depois de algum tempo esquecem completamente, tornam o aprendizado ineficaz.

\subsection{Razões para inclusão da História da Ciência no ensino de Física}

As razões para a inclusão da História da Ciência no ensino de Ciências têm raízes filosóficas e epistemológicas afirma SEQUEIRA (1988) [7]. Nesse aspecto, convêm analisar as diferentes concepções de ciências que se adaptam a História da Ciência o que dependendo da concepção adotada terá um lugar mais ou menos importante na matriz curricular e um papel mais ou menos importante no ensino de Ciências.

Partindo da hipótese de que a concepção acredite no progresso da ciência através de um método científico - que é o caso da corrente positivista e falseonista, a História da Ciência não terá um lugar de destaque, até porque colocaria em xeque à existência de um método científico que essas correntes filosóficas defendem. Caso contrário, aceitando a perspectiva do anarquismo metodológico de Feyerabend, para SEQUEIRA (1988) [7] a História da Ciência pode contribuir para demonstrar que os caminhos do progresso científico são sinuosos e o anarquismo heterodoxo são características ocasionais da ciência.

Ainda, nesse aspecto, CASTRO (1993) [8] defende a ideia que em muitos casos, algumas concepções são abandonadas ao longo da história e coincidem com o senso comum dificultando o aprendizado, então, cabe ao professor conhecer suas concepções antigas devidamente embasadas, possibilitando-o a compreender as dificuldades e resistências de seus alunos. A respeito, MATTHEWS (1995) [3], coaduna com o mesmo pensamento defendido por [8] de que o conhecimento do desenvolvimento histórico de certa disciplina pode auxiliar os professores a entender de forma mais clara as possíveis dificuldades que os alunos venham a ter com o ensino de certo assunto.

Entretanto, devem ser observadas algumas ressalvas nesta questão, uma vez que os contextos são diferentes e talvez os obstáculos ao longo da história podem não ser os mesmos que nos dias atuais.

Outra contribuição que a história traz ao ensino de Ciências é a desmitificação de alguns aspectos obscuros em certas teorias científicas e derrubar certos dogmas impostos em livros e textos didáticos presentes em sala de aula, além do fato de que a História da Ciência confronta concepções equivocadas que se tem da ciência, tais como o empiricismo e o indutivismo científico.

Além disso, segundo ZANETIC (1989) [9], a abordagem histórica da Física deve caminhar no sentido de fazer uma construção racional, crítica, polêmica, instigadora do imaginário, desveladora do secreto mundo da Física clássica e pré-clássica, que revele além dos sucessos também os fracassos ocorridos ao longo do desenvolvimento da Física, enfim, uma história que apresente o caráter dinâmico que foi característica do passado e que, certamente, com uma educação inovadora será ainda mais dinâmica.

Embora não exista evidência conclusiva, a utilização da História da Ciência no ensino de Ciências parece ser potencialmente vantajosa por dois motivos: o primeiro destes motivos tem a 
ver com a compreensão dos conceitos, princípios, leis e teorias aceitos pela comunidade científica, podendo para isso contribuir, de modo muito particular, a História da Ciência em uma abordagem internalista. Nessa abordagem, a ênfase é o desenvolvimento epistemológico da ciência, favorecendo a compreensão e o domínio sobre as teorias aceitas atualmente.

$\mathrm{O}$ outro motivo prende-se com o próprio conceito de ciência e com a atividade científica, contribuindo tanto a História da Ciência internalista quanto a externalista. Na realidade, na abordagem externalista são incluídos aspectos sociais que permeiam a construção científica.

\subsection{Elementos da narrativa da Pseudo-história e Mitos Científicos}

A Pseudo-história é um caminho que conduz à pseudociência, afirma ALLCHIN (2004) [10], ou seja, são elementos em narrativas históricas sem viés comprovadamente científico, ou pelo menos imaginário. Por exemplos, narrativas dotadas de relatos romantizados, personalidades sem defeitos, insight (estalo), ausência de qualquer erro, conclusões carregadas de ideologias e intepretação sem evidências plausíveis.

Como visto, a narrativa histórica distorcida tem uma estrutura que utiliza diversos artifícios retóricos que podem ser identificados, sendo estes responsáveis pela existência de alguns conhecidos mitos sobre descobertas científicas. Dentre inúmeras características presentes nos mais populares mitos, destacam-se alguns que formalizam sua arquitetura: grandiosidade dos cientistas, idealização sobre algumas realizações, drama afetivo durante seu desenvolvimento, e seu caráter justificativo implicando sempre em uma moral da história.

Logo, nesses mitos a ciência se baseia num método, onde os experimentos são bem projetados por pessoas extraordinárias, os cientistas, e a interpretação das evidências geradas não o traz problemas. Desta forma, a culminância científica é a verdade, sem sombra de dúvidas.

Portanto, a partir desses elementos podem-se identificar algumas narrativas com caráter pseudo-histórico que não devem ser utilizadas no ensino, principalmente aquelas que tratam os cientistas como grandes gênios, ondes suas ideias são construídas única e exclusivamente a partir de sua extrema capacidade, como afirma [10], perdendo-se as contribuições externas e as influências socioculturais e retratando apenas seus traços caricaturais e dramas pessoais.

\subsection{Os Livros Didáticos e a História da Ciência}

Os livros didáticos constituem um dos principais recursos utilizados pelos educadores em seu trabalho. Deste modo, cabe fazer uma breve consideração acerca de sua função nesse contexto.

Segundo PEDUZZI (2001) [5] não há dúvidas de que os livros textos e a sala de aula, para não falar da própria estrutura curricular, têm negligenciado o valor didático da História da Ciência, em função disso e de muitos outros problemas questionáveis sobre o livro didático se faz necessário uma análise a respeito de seu conteúdo, especificamente o conteúdo de Física.

Embora se constitua em um possível vilão ao ensino de Ciências, para BIZZO (1998) [11] é um recurso amplamente distribuído, de forma gratuita, a todas as escolas públicas do território nacional. Para ele, o livro didático pode se caracterizar como um "facilitador do processo de ensino", porém nunca como "única fonte" de consulta em que seja possível estabelecer relações com a realidade.

Inegavelmente, o livro didático tem seu status de instrumento pedagógico e auxiliador no processo de ensino-aprendizagem. Assim, algumas funções privilegiadas do livro didático ficam patentes, uma vez que é através do livro que o professor organiza e desenvolve seu trabalho pedagógico em sala.

Diante da importância atribuída ao livro didático, bem como sua ampla utilização nas escolas públicas, percebe-se que, embora alguns desses livros apresentem os aspectos históricos e filosóficos de maneira adequada, a grande maioria apresenta problemas.

Nesse aspecto, GUERRA (2009) [12] expõe que por longos anos, pesquisadores, apontaram esse recurso como sendo um dos principais responsáveis pela caracterização do ensino de Ciências como conceitualista, teórico e desvinculado da realidade.

Ressalta-se que a desvinculação da realidade acontece quando alguns autores, ao exporem tópicos históricos, normalmente não utilizam o contexto social da época em que os pesquisadores 
viveram, utilizando ainda termos que surgiram em um período temporal posterior a elaboração das descobertas.

Dentre os diversos problemas relatados nesse artigo, um especial chama atenção: a veiculação de uma Pseudo-história da ciência, que em nada contribui para o processo de construção do conhecimento científico e para a formação de conceitos e teorias de forma efetiva ao aluno.

\section{MATERIAIS E MÉTODOS}

Com a intenção de fundamentar e subsidiar uma discussão mais profunda acerca das abordagens históricas presentes em alguns livros didáticos de Física utilizados na Rede Pública de Ensino Médio do Estado do Pará, especificamente as obras que a escola Dr. Dionísio Bentes de Carvalho em Rondon do Pará (PA) utiliza, foram analisados alguns títulos constantes na lista dos aprovados do Programa Nacional do Livro Didático para o Ensino Médio (PNLEM). A análise limitou-se a quantidade e qualidade de conteúdos históricos existentes, e também com sua forma de apresentação e abordagem dentro da proposta didática de cada livro.

A Tabela 1 apresenta os livros em ordem alfabética e de seus títulos, seguidos de seus respectivos autores e ano de edições.

Tabela 1: Coleções de livros didáticos analisados e seus respectivos autores

\begin{tabular}{cccc}
\hline & \multicolumn{2}{c}{ Livros Analisados } \\
\cline { 2 - 4 } Coleção & Título & Autor & $\begin{array}{c}\text { Ano de } \\
\text { Edição }\end{array}$ \\
\hline A & Física Volume Único & Paraná, D.N. & 2000 \\
B & Cursos de Física 3 Vols. & Álvares, B.A. & 2005 \\
C & Compreendendo a Física 3 Vols. & Gaspar, A. & 2010 \\
D & Conexões com a Física 3 Vols. & Sant', A. & 2010 \\
E & Coleção Quanta Física 3 Vols. & Kantor, C. & 2010 \\
F & Física Ensino Médio 3 Vols. & Doca, R.H. & 2010 \\
\hline
\end{tabular}

Observa-se na Tabela 1 que de forma intencional a análise engloba algumas obras entre 2000 a 2010, uma vez que o objetivo é a análise da evolução dos livros didáticos nesse período.

\section{RESULTADOS E DISCUSSÕES}

Na Coleção A (Física Volume Único do Paraná, D. N. - edição de 2000) [13], há algumas distorções acerca das teorias precursoras em certos assuntos introduzindo conceitos com significados atuais, como Benjamin Franklin e sua detecção de cargas elétricas. A exemplo, o autor faz uma introdução equivocada do ponto de vista histórico no assunto de Eletrostática - p. 324. Apresenta as ideias de Benjamin Franklin com concepções atuais sobre a natureza das propriedades elétricas da matéria. Como se os átomos e os elétrons (os portadores de cargas de carga elétrica que são livres para se moverem) com se sabe atualmente foram concebidos apenas no século XX, o que seriam essas cargas que Benjamin Franklin se referia no século XVIII? Observa-se que há uma contradição extremamente equivocada nessa informação.

Na coleção B (Curso de Física: Álvares, B. A. e Luz, Antônio M. R. da - edição 2005) [14], de forma análoga a coleção $\mathrm{A}$, apresenta conteúdos históricos tanto em boxes quanto em seções específicas explanados ao longo do desenvolvimento textual, ou seja, o caráter da História da Ciência não é evidenciado como deveria.

Além do mais, na unidade 4 da obra, Física Contemporânea, os autores dedicam uma página inteira sobre Albert Einsten. Enobrecem a figura do cientista apresentando-o como um superhumano: O grande físico Albert Einsten [...], além de retratar a história distorcida ao atribuir a ele a maioria das ideias, sem considerar a contribuição dos outros pesquisadores e os motivos que levaram à aceitação das teorias atuais em detrimento das outras possibilidades existentes no período. Há referências histórias sobre os outros cientistas como Schroedinger, de Broglie, Bohr, 
Heisenberg, entre outros, apenas de cunho biográfico, sendo o texto mais aprofundado o texto sobre Albert Einsten.

Ao ler a passagem constante na p. 14 do volume 3 da coleção: "O famoso político e cientista americano Benjamin Franklin, após realizar um grande número de observações experimentais, constatou que, quando dois corpos são atritados um contra ou outro, se um deles se eletrizar positivamente, o outro, necessariamente, irá adquirir carga elétrica negativa. [...] Procurando uma explicação para este fato, Franklin formulou uma teoria segundo a qual os fenômenos elétricos eram produzidos pela existência de um fluido elétrico que estaria presente em todos os corpos. Em um corpo não eletrizado (corpo neutro) este fluido existiria em "quantidade normal", a primeira impressão a respeito é que Franklin sofreu uma espécie de Insight, achei, encontrei, eureca! introduz diversos erros, principalmente ao desconsiderar as teorias existentes e as concepções sobre a natureza dos fenômenos elétricos na época em questão.

Os estudos de Franklin e seu conhecimento sobre o tema foram influenciados fortemente por trabalhos anteriores e estudiosos como Du Fay, Gilbert, entre outros, sequer foram mencionados pela coleção nesse assunto.

Encontram-se vários outros erros em relação aos conteúdos históricos apresentados pela coleção B, como o mito de Arquimedes e seu grito de eureca na banheira.

Uma característica marcante na coleção C [15] é a presença de conteúdos históricos em praticamente todos os capítulos e pode-se dizer que a forma principal de apresentação foi através de boxes. Estes boxes estão recheados de informações acerca de cientistas e seus trabalhos, bem como a importância para sua época e a relação com o conhecimento atualmente aceito. Porém, a forma como estes conteúdos são tratados privilegiam as ideias aceitas atualmente e, no geral, ignoram a contribuição de outros pesquisadores. Destaca-se ainda nessa coleção, as seções conhecendo um pouco mais cujo teor histórico é abundante. Não se verificou a presença de mitos nos textos abordados.

Na coleção D (Conexões com a Física: Sant' Anna, Blaidi et al - Edição 2010) [16] observa-se a ausência de boxes, o que diferencia-se em relação as outras coleções. Apenas nos finais de cada capítulo a seções Para saber mais abordam de forma resumida alguns fatores históricos em relação a tema visto nas unidades. A coleção apresenta traços fortes de Pseudo-história na unidade 1 do volume 1, quando conta a experiência de Galileu na Torre de Pizza e traz uma ilustração para reforçar o mito, não há evidências de discussões, debates, ou questionamentos acerca do experimento de Galileu. Um ponto positivo na coleção é quando a apresentação das Leis de Kleper, os autores abordam as teorias Geocêntricas e Heliocêntricas com uma fundamentação em que o conteúdo ordinário realmente é abordado, sem enobrecer a figura do cientista ou evidenciar qualquer forma de heroísmo científico.

Nas demais unidades do volume 1, nota-se a ausência de elementos históricos, apenas complementações nas seções já citadas, o que para esclarecimento da construção do conhecimento científico torna-se insuficiente para um aprendizado significativo.

Os assuntos de forma geral têm seu início numa abordagem histórica resumida e os textos complementares sobre a História da Ciência e questões interdisciplinares são pouco exploradas.

A presença marcante na coleção E (Quanta Física: Kantor, Carlos A. - Edição 2010) [16] de conteúdos históricos é maciça em praticamente todos os capítulos da coleção, além da forma de apresentação através de boxes informativos e contextualizados, existem as seções conexão que interdisciplinarmente complementam a abordagem cientifica do conteúdo principal.

Ao contrário das outras coleções, salvo com algumas exceções, em que se encontram um mito bastante popular; a suposta observação de um pêndulo por Galileu, essa coleção não coaduna com mesma observação. Em nenhum ponto, observa-se a presença de elementos de arquitetura Pseudo-histórica ou apenas menções bibliográficas.

A coleção F (Física Ensino Médio: Doca, Ricardo Helou et al. - Edição 2010) [18] mostra em toda sua extensão conteúdo históricos em todos os capítulos da coleção, e mais boxes explicativos, interdisciplinares e seções com textos complementares que complementam a abordagem cientifica ordinária. Logo, no início da obra, especificamente, no volume, os autores destacam a importância da Física na natureza e na tecnologia, enfatizando multidisciplinarmente o uso da Física em vários cenários científicos: na medicina, nas artes, na cultura, no direito, dentre outros. 
É notório nessa coleção, o nível dos textos para leitura. Ainda nas unidades iniciais acerca da Cinemática, já apresentam elementos de leitura acerca da velocidade da luz, o que de modo é coerente e sua abordagem histórica remonta ao método experimental apresentado primordialmente por Galileu, pelo qual os autores fazem apenas uma breve menção. Elencam nessa observação, a importância de outros cientistas como Römer, Fizeau, Focault e Michelson.

Identifica-se nessa coleção a presença de mitos, textualmente na p.131 o autor afirma "Enfim, quem teve importância maior, Newton ou Einstein? Não há dúvida de que a resposta é: ambos! Esses dois gênios da ciência influenciaram, cada um em seu tempo, todo um modo de pensar e proceder, permitindo que a humanidade compreende-se a natureza mais profundamente."

É inquestionável a importância de Newton e Einsten para o desenvolvimento da ciência, porém atribuir a ambos o grande feito de fazer a humanidade compreender a natureza é no mínimo utópico. E os demais cientistas? Não tiveram a mesma importância nesse processo de compreensão humana acerca da natureza? No fragmento "[...] Esses dois gênios da ciência [...]" caracteriza-se o elemento grandiosidade e em "[...] permitindo que a humanidade compreende-se a natureza mais profundamente [...]", refere-se ao elemento de mito idealização.

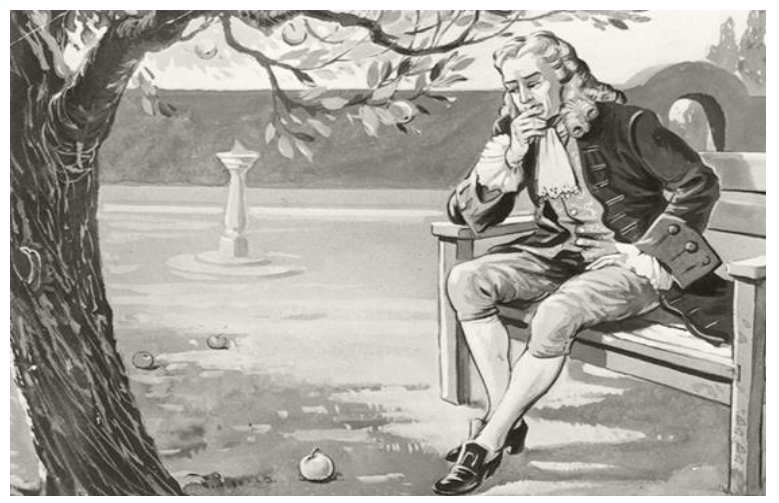

Figura 1: Representação artística do mito científico de Isaac Newton e a maça Fonte: http://wordpress.com

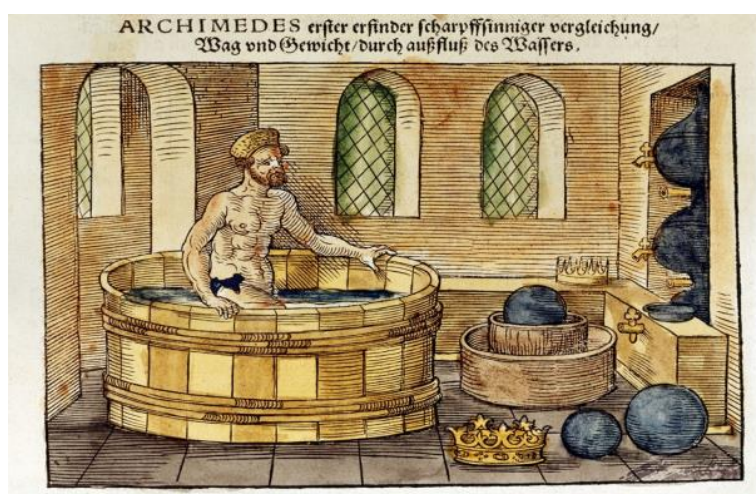

Figura 2: Ilustração do mito científico de Arquimedes e a banheira Fonte: http://wordpress.com

No capítulo 14 na p. 405, o tema Estática dos Fluídos, há um texto complementar intitulado Um banho revelador que traz a tona o mito científico de Arquimedes e a banheira. Obviamente, não há comprovações históricas que realmente esse fato tenha ocorrido. Aliás, os autores se eximem de identificar a fonte de pesquisa a que ser refere o texto.

De uma maneira geral, ao final da análise das coleções didáticas, nota-se que praticamente quase todas as coleções apresentam elementos de mitos históricos. Conforme os exemplos discutidos, observou-se que a História da Ciência que se faz mais presente nas coleções de Física de modo geral, apresentam mitos como: Isaac Newton e a maça, Arquimedes e a banheira, Benjamin Franklin e sua pipa, etc, além de uma forma comum de apresentação dos conceitos históricos através de boxes e seções informativas. 


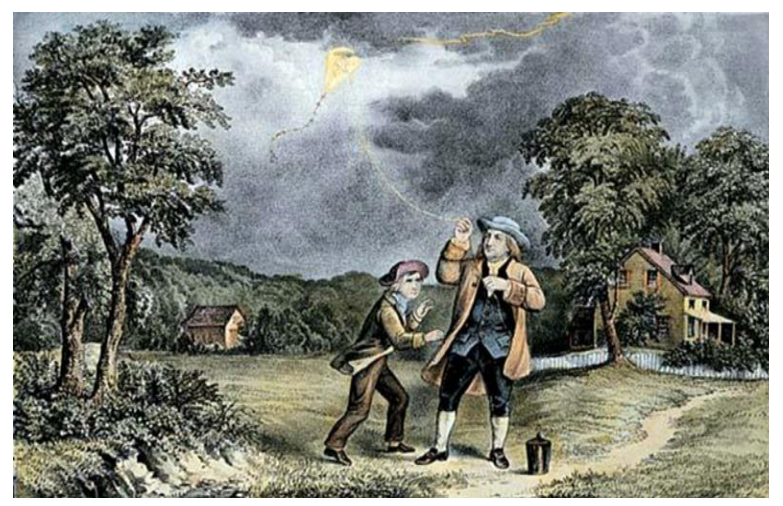

Figura 3: Ilustração do mito científico de Benjamin Franklin e sua pipa Fonte: http://www.pakequis.com.br/

Em todos os títulos também se verifica a presença da pseudo-histórica da ciência, onde elementos históricos são distorcidos das mais variadas formas, sobretudo quando conhecimentos atuais são usados para explicar a elaboração de teorias e interpretações de experimentos anteriores já devidamente explicados.

\section{CONCLUSÃO}

Alvo frequente de discussões e pesquisas, a inserção da História da Ciência como estratégia metodológica na educação, principalmente no ensino-aprendizagem de Física, vem ganhando notoriedade entre pesquisadores nas últimas décadas. Apesar de que alguns acreditem que sua utilização possa apresentar certas limitações, há aqueles que defendem veementemente sua importância no ensino. Considerações a respeito da inserção de elementos de História da Ciência na educação científica em seus diversos níveis são hoje uma realidade e as pesquisas com os mais variados públicos têm sido realizadas nos últimos anos.

Estas pesquisas apontam pontos positivos que consideram a História da Ciência como parte integrante do ensino científico. Sua forma contextualizada fornece subsídios importantes que contribuem na formação e compreensão do real significado de conceitos científicos, sua origem e seus propósitos, auxiliam o aluno a desenvolver uma melhor compreensão da natureza da Ciência e dos processos envolvidos na construção do conhecimento científico.

Nessa perspectiva, a História da Ciência desempenha um papel estrutural na organização do conhecimento, apresentando-se não como uma simples metodologia ou mais um elemento didático-pedagógico, porém como uma ferramenta eficaz quanto ao processo de ensinoaprendizagem de Física.

Um aspecto que não se pode deixar de lado nesse processo, é que consensualmente há uma preocupação na abordagem da História da Ciência quanto às habilidades cognitivas dos estudantes. Neste trabalho, houve a preocupação a respeito e foram feitas observações dos vários enfoques em algumas teorias de Ensino.

A partir da observação desses aspectos e dos diversos trabalhos de pesquisa desenvolvidos, evidencia-se a importância da História da Ciência no ensino de Ciências, seu potencial e as possibilidades em questão quanto a sua utilização. Ressalta-se ainda que se faz necessário existir um diálogo mais aprofundado entre os autores de livros didáticos de ciências, professores e pesquisadores das áreas de história, filosófica e ensino de Ciências, com essa aproximação, é possível que haja uma influência positiva no sentido de melhorar o conteúdo dos livros, diminuir a quantidade de erros e favorecer a transmissão de uma visão adequada sobre a natureza da Ciência adquirida através da História da Ciência.

Ressalta-se que com intuito de implementar a proposta de inserção da História da Ciência em uma Base Curricular Comum, implica-se em uma revisão total não apenas do conteúdo exclusivamente técnico, mas também da forma como os tópicos devem ser incluídos nos currículos de ciências, aliás, nesse aspecto, a contribuição será significativa, de forma que venham a influenciar positivamente na elaboração dos livros didáticos, evitando 
consequentemente a presença maciça de elementos e mitos Pseudo-históricos em seu contexto e que em nada contribuem para o aprendizado em Ciências, especialmente, no caso da Física.

\section{AGRADECIMENTOS}

A todos os professores da Unifesspa que contribuíram para minha formação acadêmica.

\section{REFERÊNCIAS BIBLIOGRÁFICAS}

1. Neves MCD, O Resgate de uma História para o Ensino de Física. Cadernos Catarinenses de Ensino, Paraná: UEM/Departamento de Física, v.9, n.3, 1992. p. 215-224

2. Bassalo JMF, A importância do Estudo da História da Ciência. Revista da SBHC. n.8, 1992. p. 57-66.

3. Matthews MR, História, filosofia e Ensino de Ciências: a tendência atual de reaproximação. Caderno Brasileiro de Ensino de Física. Auckland Nova Zelândia. V.12, n.3, 1995. p.164-214.

4. Brasil ME, Secretaria de Educação Média e Tecnológica. Parâmetros Curriculares Nacionais: Ensino Médio. Brasília: MEC; 2000. 58 p.

5. Peduzzi LOQ, Martins AFP, Ferreira, JMH, Temas de História e Filosofia da Ciência no Ensino. UFRN, Natal: EDUFRN; 2012. 374 p.

6. Ausubel DP, Novak JD, Hanesian H, Psicologia Educacional. Rio de Janeiro: Interamericana; 1980, 117 p.

7. Sequeira M, Leite L, A História da Ciência no ensino-aprendizagem das Ciências. Revista Portuguesa de Educação. Universidade de Minho. Portugal, 1988, p. 29-40.

8. Castro RS, História e Epistemologia da Ciência: Investigando suas contribuições num curso de Física do Segundo Grau. [dissertação] - Instituto de Física e Faculdade de Educação, Universidade de São Paulo, São Paulo; 1993. 155 p.

9. Zanetic J, Mesa Redonda: Influência da História da Ciência no Ensino de Física. In: Caderno Catarinense de Ensino de Física. Florianópolis 1998 jun;5 (Nmero especial):76-92.

10. Allchin D, Pseudo history and Pseudoscience. Science \& Education; 2004 April;13(3):179-195, doi: 10.1023/B:SCED.0000025563.35883.e9

11. Bizzo N, Ciências: fácil ou difícil? São Paulo: Ática; 1998. 381 p.

12. Guerra A, Quintal JR, A História da Ciência no processo de ensino-aprendizagem. Física na Escola 2009 maio;10(1):21-25.

13. Paraná DN. Física para o Ensino Médio - volume único. São Paulo: Editora Ática; 2000.

14. Alvares BA, Luz AMR. Curso de Física. Volumes 1,2 e 3. São Paulo: Saraiva; 2005.

15. Gaspar A. Compreendendo a Física. Volumes 1, 2 e 3. São Paulo: Ática; 2010.

16. Sant'Anna, B. Conexões com a Física. Volumes 1,2 e 3. São Paulo: Moderna; 2010.

17. Kantor CA. Coleção Quanta Física. Volumes 1, 2 e 3. São Paulo: PD; 2010.

18. Doca RH, Villas Boas N, Biscuola GJ. Física Ensino Médio, Volumes 1,2 e 3. São Paulo: Saraiva; 2010. 